\title{
THE USE OF THREE RECYCLING METHODS FOR REBONDING OF CERAMIC BRACKETS
}

\author{
Mohamed E. Yousef ${ }^{1}$, Hanan A. Ismail ${ }^{2}$, \\ Eiman S. Marzouk ${ }^{3}$, Mostafa A. Shelib ${ }^{4}$
}

\section{ABSTRACT:}

Objective: The aim of this study was to compare the effect of three recycling methods - Tribochemical silica coating combined with silane, conventional sandblasting combined with silane, and heat application combined with silane - on the shear bond strength of rebonded ceramic bracket compared to newly bonded brackets. Materials and Methods: Sixty chemically retentive ceramic bracket (inspire ICE) were divided into four groups (15 in each group): Control new brackets (without silane), sand6lasting using $50 \mu \mathrm{m}$ aluminum oxide + silane, sandblasting using $30 \mu \mathrm{m}$ silica coated aluminum oxide (Tribochemical silica) and heat treatment + silane. All brackets were thermocycled 5000 times between $5{ }^{\circ} \mathrm{C}$ and $55^{\circ} \mathrm{C}$. Shear force was applied to the enamel-adhesive interface until de6onding. Results: The highest bond strength was found in the heat + silane group and the new control brackets (19.5 and 19.2 MMPa, respectively) followed by the silica coated aluminum oxide + silane (11.8 MPa). Recycling using $50 \mu \mathrm{m}$ aluminum oxide + silane resulted in significantly low bond strength (1.5 MMPa). Conclusion: $\mathcal{N}$ o significant difference in the SBS between heat treated group

1- Post graduate student, Orthodontics department, Faculty of Dentistry, Alexandria University

2- Professor of Orthodontics Faculty of Dentistry, Alexandria University

3- Lecturer of Orthodontics, Faculty of Dentistry, Alexandria University

4- Assistant Professor of Biomaterial, Faculty of Dentistry, Alexandria University 
Egyptian

Orthodontic Journal

followed by silane application and $30 \mu \mathrm{m}$ silica coated sand6lasted group. Reconditioning with $30 \mu \mathrm{m}$ silica coated sandblast is a promising method as it is chair-side time-effective and show good comparable SBS to that of new brackets.

\section{INTRODUCTION}

Orthodontic treatment with fixed appliances requires fixing brackets on enamel surface to enable a force system to be applied to the teeth. Brackets provide these attachments to the teeth. Orthodontic Brackets withstand masticatory forces by the mean of bonding material that provides sufficient shear bond strength (SBS). Therefore, when a bracket is not bonded with high-quality materials, masticatory forces exceed the norm or due to possible errors during bracket bonding, the bracket may dislodge or break during the treatment. Bracket debonding is a problem facing every orthodontist as the bond failures affect treatment efficiency, have economic impact and delaying of treatment.

Development of Orthodontic brackets also has an effect on bond strength and bonding procedures. Esthetics play an important role in the development of brackets, the expectation of beautiful smiles at the end of orthodontic treatment is a primary concern to each patient, who is also concerned about appearance while undergoing treatment. Many attempts have been made by manufacturers to meet this demand. This includes: reducing the size of metal brackets, developing lingual technique or introducing plastic brackets, aligners and introducing translucent ceramic brackets. Plastic brackets were marketed as an esthetic alternative to metal brackets. These polycarbonate brackets quickly lost favor because of discoloration and slot distortion caused by water absorption..$^{1-4}$ This led manufacturers to modify the plastic brackets by reinforcing the slots with metal and ceramic fillers ${ }^{5}$. Despite these alterations, the clinical problems like distortion and discoloration persisted. 
Egyptian

Orthodontic Journal

In the mid-1980s, the first brackets made of monocrystalline sapphire and polycrystalline ceramic materials came into the field of orthodontics. Aluminum oxide, the main component of the ceramic brackets, is an inert material; it cannot chemically adhere directly to any of the currently available bonding resins. For this reason, two different basic mechanisms were developed by which ceramic brackets could be attached to the adhesive. The first mechanism with the earlier ceramic brackets was the chemical form of retention. The bases of these ceramic brackets were coated with silane to obtain a chemical bond between the bracket and the adhesive. Increased bond strength with ceramic brackets resulted in bond failure at the enamel-adhesive interface, rather than at the bracket-adhesive interface causing enamel fractures when debonding these brackets. ${ }^{6,7}$ The second mechanism in an effort to prevent enamel fracture while debonding, a new generation of ceramic brackets that get their retention from mechanical undercuts was produced, which have significantly less bond strength than chemically retentive ceramic brackets. ${ }^{8,9}$ Finally, there are nowadays three different retention mechanisms by which ceramic brackets can be attached to the bonding agent, chemical retention using silane, mechanical retention, and a combination of both methods.

Bracket failure is an event that orthodontists face frequently during orthodontic treatment. Bracket failures have many reasons; it may be due to poor bonding technique including improper cleaning of enamel surface before bonding, failure to control saliva during bonding procedures, improper etching time either short etching time or long etching time, using a thick film of sealant that interferes with bracket base positioning and improper positioning, seating of bracket and removal of excess. Other reasons of bracket failure may be due to the patient high masticatory forces, bad habits producing heavy forces on the bracket. A simple chair-side method was described by Lew and Djeng ${ }^{10}$ in 1990 , their technique was to remove any composite resin remaining on the chemically retentive ceramic bracket base using mini-Torch. The mean 
Egyptian

Orthodontic Journal

bond strength of the recycled ceramic brackets with this method was $40 \%$ to $50 \%$ lower than that of the new brackets, although it is within clinically acceptable limits. ${ }^{10,11}$

To improve the adhesion to porcelain restorations or dental devices, specific surface-conditioning methods have been developed. Hydrofluoric acid etching roughens the porcelain surface, providing a retentive surface for better bonding; this procedure is recommended as the standard when bonding a bracket to a porcelain surface. ${ }^{12}$ However, using hydrofluoric acid as a ceramic bracket-base conditioner resulted in significant reduction in bond strength $(0.7-1.6 \mathrm{MPa})$ and therefore cannot be recommended for clinical use. ${ }^{13,14}$

Another conditioning method is the airborne particle abrasion; this has been reported to create microretentive surfaces in metals and other dental materials whenever needed. ${ }^{15}$ Although initially reintroduced as a method to roughen the surface of many dental materials before cementation to enhance bond strength. ${ }^{16,17}$ More recently air abrasion is being used in orthodontics to roughen the internal surfaces of bands, bracket bases and enamel surface. Sandblasting of dental restorations is often used to clean the surfaces of materials and to achieve fine, roughened surface topography and increased surface area. ${ }^{18-22}$

Sandblasting the debonded ceramic bracket bases before rebonding has been studied as a surface-treatment technique and resulted in a lower SBS than new brackets. ${ }^{14}$

Application of silane after sandblasting for improving the SBS was studied by many authors, controversy found in literature as silane was reported to decrease $\mathrm{SBS}^{23}$, also reported to increase in the $\mathrm{SBS}^{24,25}$ and reported that it had no effect on $\mathrm{SBS}^{14}$

Another abrasive system is the silica coated aluminum oxide (Tribochemical silica) that provides not only a mechanical way of retention but also chemical retention used by few authors reported its superiority on the conventional sandblast (Aluminum oxide) ${ }^{23,26,27}$. Our hypothesis was that there was no difference in the SBS between rebonded 
Egyptian

Orthodontic Journal

ceramic brackets using $30 \mu \mathrm{m}$ tribochemical silica sandblasting, conventional $50 \mu \mathrm{m}$ sandblasting and heat application all combined with silane for recycling. Therefore the aim of this study was to compare the effect of three recycling methods - Tribochemical silica coating combined with silane, conventional sandblasting combined with silane and heat application combined with silane - on the shear bond strength of rebonded ceramic bracket compared to newly bonded brackets.

\section{MATERIAL AND METHODS}

Using a power of $80 \%$ to detect a clinically significant difference in the SBS of rebonded ceramic bracket $=2.9 \mathrm{MPa}$ with standard deviation in heat group $=3.7$ while in silica coated aluminum oxide group $=3.8$. The minimal total required sample size was calculated to be 56 to be divided on the studied groups. The sample size was calculated using G.Power software. ${ }^{28}$ Sixty extracted human premolar teeth were used to address the study aim. They were collected in distilled deionized water. The inclusion criteria for tooth selection were: intact buccal enamel, no previous treatment with any chemical agent, no caries and no hypo-calcification.

Mechanically retentive ceramic brackets (Inspire ICE) were used in this study where the debonded bracket was obtained by bonding the bracket with composite resin on an unetched wet enamel surface. The brackets were light-cured for 20 seconds. The bonded brackets were then separated from the tooth surface easily using a tweezer with light pressure.

All teeth were cleaned from soft tissue, and the buccal surface of each tooth was polished with a nonfluoridated pumice slurry and rubber prophylactic cups for 10 seconds. All Brackets were bonded to a virgin enamel surface (without previous bonding). Teeth were divided randomly in to four groups to be bonded to the ceramic brackets: Control group (new brackets without silane application), recycled brackets using $50 \mu \mathrm{m}$ aluminum oxide particles + silane, recycled bracket using $30 \mu \mathrm{m}$ silica coated aluminum oxide particles + silane and lastly recycled brackets using heat + silane. 
Egyptian

Orthodontic Journal

Sandblasting with both $50 \mu \mathrm{m}$ aluminum oxide particles and $30 \mu \mathrm{m}$ silica coated aluminum oxide particles was done vertically from a distance of $10 \mathrm{~mm}$ using an intraoral sandblaster filled with either abrasive particle. Both procedures persisted until the bonding resin was totally removed from the bracket base and became no longer visible to the naked eye, then checked under a stereo microscope at a 10x magnification. Heat application was performed by placing the brackets in a furnace with a preadjusted temperature at $450 \mathrm{C}^{\mathrm{o}}$ for 1 hour for burning the remaining composite on the bracket, and then the brackets were put in an ultrasonic bath with alcohol for cleaning any remaining composite.

The buccal enamel surfaces were etched with $37 \%$ phosphoric acid gel for 30 seconds, thoroughly rinsed in water and dried for 20 seconds. Ortho Solo Sealant was applied to the etched area, light cured for 10 seconds. After that the silane was applied to the conditioned bracket base and allowed to dry for 3 minutes. Next, the brackets were bonded using blugloo composite resin $\&$ placed on the tooth surfaces by using a bracket holder under manual control. The excess resin was carefully removed from around the bracket base, and the adhesive resin was light cured for 40 seconds.

The bonded teeth were stored in distilled deionized water for 24 hours at room temperature. Then they were thermocycled 5000 times between $5^{\circ} \mathrm{C} \pm 2^{\circ} \mathrm{C}$ and $55^{\circ} \mathrm{C} \pm 2^{\circ} \mathrm{C}$ with a transfer time of 5 seconds and a dwell time of 20 seconds in each bath.

After thermocycling they were embedded in resin using previously milled brass block for that purpose, with a diameter that is slightly less than the testing machine holding ring, where the block was inserted to avoid any discrepancy in size due to resin setting. Each tooth was mounted in self-cure acrylic resin using the milled brass block with the use of the surveyor to precisely insert all the specimens in the 
Egyptian

Orthodontic Journal

acrylic resin in an upright position to the cemento-enamel junction. A $0.021 \times 0.025$ stainless steel wire soldered in a cross shape with the long arm fixed in the surveyor and the short arm used to ligate the bracket bonded on the tooth to accurately insert all the teeth in the same position.

The SBS testing was performed using a universal testing machine where each specimen was fixed on a holding ring positioned in the lower table of the universal testing machine. A chisel was secured to the upper table \& applied perpendicularly between the bracket base and the tooth with a crosshead speed of $0.5 \mathrm{~mm}$ per minute to shear the bracket off the tooth surface. The force required to debond each bracket was recorded in Kilograms on a monitor attached to the machine, and converted to megapascals (MPa) by dividing by the bracket base surface area which was calculated by measuring the length and width of the bracket by Boley caliper gauge and was found to be $10.5 \mathrm{~mm}^{2} .{ }^{29,30} \mathrm{~A}$ scanning electron microscope (SEM) examination was also done on representative samples from all groups.

The SBS value of each group was collected and tabulated. Descriptive statistics including the mean, standard deviation, minimum, and maximum were calculated, and the data was statistically analyzed by one-way analysis of variance (ANOVA) and Bonferroni post hoc tests $(\alpha=0.05)$.

\section{RESULTS}

The descriptive statistics for the 4 groups are presented in Table I and figure 1 showed that the SBS for the control new bracket was $(19.2 \pm 9.8 \mathrm{MPa})$ while the SBS for the recycled group was: $(19.5 \pm 11.1 \mathrm{MPa})$ for the heat group, $(11.8 \pm 10.7 \mathrm{MPa})$ for the $30 \mu \mathrm{m}$ silica coated aluminum oxide group and $(1.5 \pm 1.7 \mathrm{MPa})$ for the $50 \mu \mathrm{m}$ sandblasting group. 
Comparing the SBS of the control new bracket to the recycled groups revealed the heat treated group showed higher SBS than the control group. While, the silica group showed lower mean SBS than control group but still clinically applicable. While, $50 \mu \mathrm{m}$ sandblasting group showed lower mean SBS that is not clinically accepted.

Table I. Descriptive statistics and the results of the ANOVA comparing the SBSs of the 4 groups

\begin{tabular}{|lccccc|}
\hline Groups & N & $\begin{array}{c}\text { Mean SBS } \\
(\mathbf{M P a})\end{array}$ & SD & Min. & Max. \\
\hline $\mathbf{5 0} \boldsymbol{\mu m}$ sandblasting & 15 & 1.5339 & 1.79882 & .00 & 6.82 \\
\hline $\mathbf{3 0} \boldsymbol{\mu m}$ Sandblasting & 15 & 11.8339 & 10.76026 & 0.43 & 46.10 \\
\hline Heat & 15 & 19.5489 & 11.10183 & 4.94 & 40.73 \\
\hline Control & 15 & 19.2023 & 9.85819 & 7.24 & 39.11 \\
\hline
\end{tabular}

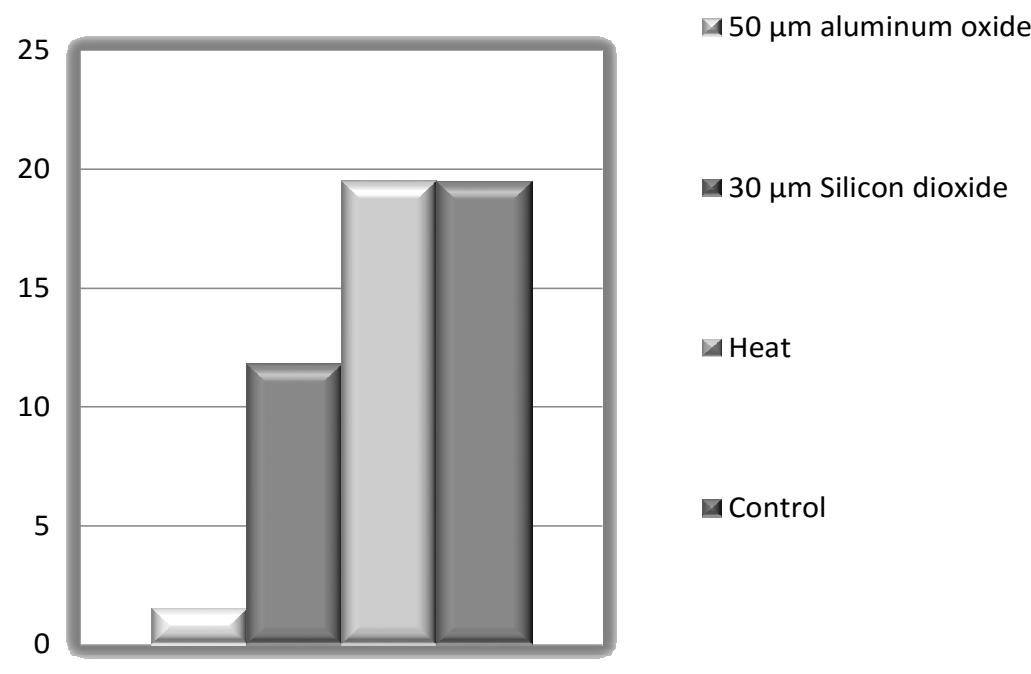

Fig 1. Histogram showing the mean SBS of all groups 
Statistical analysis using ANOVA test shown in table II revealed that there was significant difference in the SBS between the four groups used $(\mathrm{F}$ value $=12.619$ and $\mathrm{P}$ value $=0.000)$. Statistical analysis among the tested groups using Post Hoc test shown in table II showed a statistically significant difference $(\mathrm{P} \leq .05)$ between: 1$)$ heat group and $50 \mu \mathrm{m}$ sandblasting group and 2) control group and $50 \mu \mathrm{m}$ sandblasting group, 3) Silica coated group $(30 \mu \mathrm{m})$ and $50 \mu \mathrm{m}$ sandblasting group. There was no significant difference between: 1) Silica coated group $(30 \mu \mathrm{m})$ and control group, 2) Silica coated group ( $30 \mu \mathrm{m})$ and heat group.

Table II. Bonferroni post hoc tests for all groups

\begin{tabular}{|lccc}
\hline (I)Surface Cleaning & $(\mathbf{J})$ Surface Cleaning & $\begin{array}{c}\text { Mean } \\
\text { Difference }\end{array}$ & Significance \\
\hline \multirow{5}{*}{$\boldsymbol{5 0 m}$ Sandblasting } & $30 \mu \mathrm{m}$ Blasting & $-10.29994^{*}$ & .020 \\
& Heat Burn & $-18.01496^{*}$ & .000 \\
& Control & $-17.66841^{*}$ & .000 \\
$\mathbf{3 0} \boldsymbol{\mu m}$ Sandblasting & Heat burn & -7.71501 & .154 \\
& Control & -7.36846 & .196 \\
\hline \multirow{2}{*}{ Heat } & $50 \mu \mathrm{m}$ Blasting & $10.29994^{*}$ & .020 \\
& $30 \mu \mathrm{m}$ blasting & 7.71501 & .154 \\
& Control & .34655 & 1.000 \\
\hline Control & $50 \mu \mathrm{m}$ Blasting & $18.01496^{*}$ & .000 \\
& $30 \mu \mathrm{m}$ Blasting & 7.36846 & .196 \\
& Heat Burn & -.34655 & 1.000 \\
& $50 \mu \mathrm{m}$ Blasting & $17.66841^{*}$ & .000
\end{tabular}

* Significant difference $\mathrm{P} \leq 0.05$ 


\section{Egyptian}

Orthodontic Journal
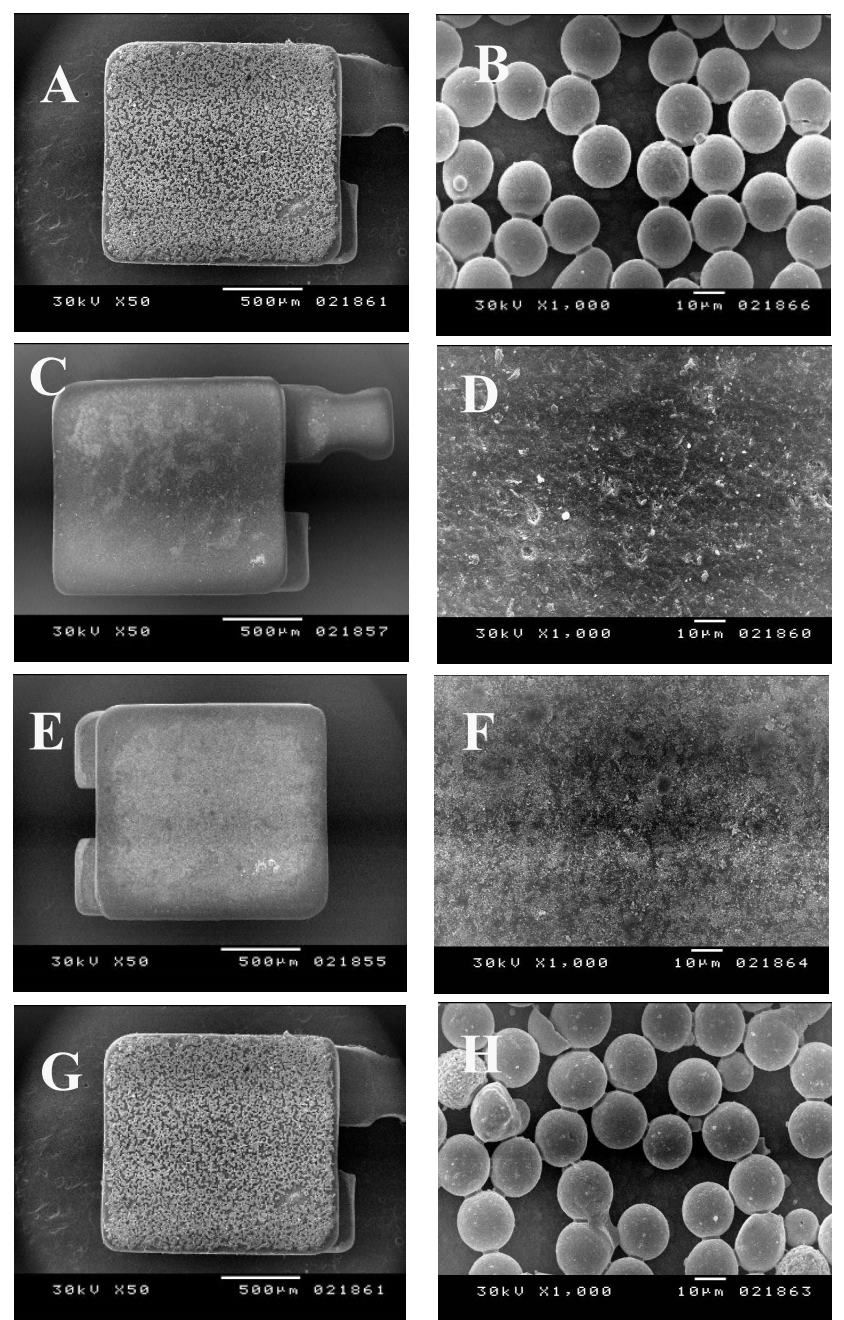

Fig 2. SEM views of representative samples of bracket bases: A and B new Inspire bracket showing the ball pattern mean of retention (50 and 1000 times magnification); $\mathrm{C}$ and $\mathrm{D}, 50 \mu \mathrm{m}$ aluminum oxide particles (50 and 1000 times magnifications, respectively); E and F, $30 \mu \mathrm{m}$ silica coated (50 and 1000 times magnifications, respectively); $\mathrm{G}$ and $\mathrm{H}$ heat treatment (50 and 1000 times magnifications, respectively). 
Egyptian

Orthodontic Journal

Removal of the excess of adhesive material with either abrasive technique; aluminum oxide or silica coated aluminum oxide takes approximately 30 seconds to remove all the visible adhesives on the bracket base. It could be observed with the naked eye that the bracket base changed after the sandblasting or silica coating processes, where both techniques generated smooth bracket-base surfaces, when compared with the original ball-base surface of the new bracket. While the heat treated group showed the same pattern like the original bracket supplied by manufacturer as shown in figure 2 .

However, (SEM) visualizations under higher magnification (1000 X) showed differences between the two abrasive systems on the bracket-base surfaces. The silica-coating procedure created superficial irregularities and shallow erosions on the bracket-base surface. Whereas, sandblasting created slightly more prominent irregularities and deeper erosions. While the heat treated group was the only group the original pattern supplied by manufacturer as shown in figure 2.

\section{DISCUSSION}

Ceramic brackets are gaining popularity among patients because large numbers of patients are seeking more esthetic orthodontic treatment. However, replacing a failed bracket with new a one is expensive so recycling provides a benefit of reducing cost. This study was carried out to determine the bond strengths of rebonded mechanically retentive ceramic brackets using various recycling procedures.

Longevity of brackets is predicted to some extent by its adhesive ability and adhesive bond strength can be measured by bond strength testing. An ideal bond strength test should be accurate, clinically reliable, and less technique-sensitive. A lot of variables influence the test outcome, they are categorized into substrate-related factors, factors related to specimen properties, preparation of specimens, and test methodology. ${ }^{31}$ In this study we tried to minimize variables as much as possible. Due to the inadequate availability of human teeth, animal teeth were used in many invitro studies ${ }^{32-34}$ Controversy in literature was found concerning the SBS of bovine teeth and its similarity to human teeth. In this study, human extracted tooth were used to avoid any variability in our results. 
Egyptian

Orthodontic Journal

Several types of storage media were used in literature for testing the bond strength such as: Distilled water, saline, $0.05 \%$ saturated solution of thymol, $0.5 \%$ chloramine-T, $2 \%$ gluteraldehyde, and $10 \%$ formalin solutions. ${ }^{35,36}$ Storage in sodium hypochlorite $(\mathrm{NaOCl})$ resulted in lower bond strengths, while sterilization with the autoclave negatively affected the bond strength. Storage in 10\% formalin resulted in varied bond strengths. ${ }^{37,38}$ According to the ISO technical specification 11405 , bond strengths should be measured immediately post-extraction but not more than six months. ${ }^{39}$ In this study, all specimens were stored in distilled water and the bond strength measurement was performed at three month post-extraction to the maximum.

All specimens were thermocycled for 5000 times between $5^{\circ} \mathrm{C} \pm 2{ }^{\circ} \mathrm{C}$ and $55^{\circ} \mathrm{C} \pm 2^{\circ} \mathrm{C}$ with a transfer time of 5 seconds and a dwell time of 20 seconds in each bath to simulate the same condition of the oral cavity. The bonding procedures were carried out by the same operator to minimize technique inconsistencies.

Different cross-head speeds may influence the SBS. ${ }^{40}$ SBS using crosshead speeds of $0.50 \mathrm{~mm} / \mathrm{min}$ and $0.75 \mathrm{~mm} / \mathrm{min}$ should be preferred due to their better cohesive versus adhesive results. ${ }^{41}$ In this study, the testing machine was turned on at a crosshead speed of $0.5 \mathrm{~mm}$ per minute to shear the bracket off the tooth surface.

Inspire ICE brackets used in this study are monocrystalline sapphire translucent true twin brackets, made by Boron carbide tumbling process and ultra-smooth heat polished surface, with a mechanical ball base design for mechanical retention. ${ }^{42}$ It is obtained from $\mathrm{Zr}_{2} \mathrm{O}$ (zirconium oxide) yttrium stabilized. On the bracket base surface, big rounded microretentions of $30 \mu \mathrm{m}$ diameter agglutinated in-between can be seen. ${ }^{43}$ The balls and the spaces between them provide space for the adhesive to achieve adequate bonding. These ball shaped structures get lost by the recycling method in this study except for the heating method which preserved the manufacturer supplied pattern as shown in figure 2. The relative bracket base surface area was recorded using a simple method which was: measuring the length and width of the bracket by Boley caliper gauge neglecting the curvature of the bracket base as it was decided to have a negligible effect on the whole result. 
Egyptian

Orthodontic Journal

Using $50 \mu \mathrm{m}$ aluminum oxide particles for removal of the remaining adhesive on the bracket surface resulted in a smooth bracket base surface and complete destruction of the bracket base pattern supplied by the manufacturer. This method does not take much more than 30 seconds to remove all visible adhesives on the bracket base. SEM examination showed superficial irregularities on the ceramic bracket-base surface as shown in figure (2), but a significantly low SBS $(1.5 \pm 1.7 \mathrm{MPa})$ compared to all groups of recycling in this study. Similar results were reported by Chung et $\mathrm{al}^{14}$ and Atsü et $\mathrm{al}^{27}$, while clinically acceptable results were reported by Toroglu and Yaylali ${ }^{26}$ and Frank et $\mathrm{al}^{24}$.

Using $30 \mu \mathrm{m}$ silica coated aluminum oxide abrasive particles resulted in a visible smooth surface of the bracket base and destruction of the manufacturer supplied pattern. Removal of the adhesives from the bracket base took about 30 seconds. SEM visualization of bracket base showed less prominent irregularities than done by the $50 \mu \mathrm{m}$ aluminum oxide group fig (11), but the mean SBS for this group $(11.8 \pm 10.7 \mathrm{MPa})$ showed a significantly high value compared to the $50 \mu \mathrm{m}$ sandblasting group $(1.5 \pm 1.7 \mathrm{MPa})$. Our results agreed with literature in that tribochemical silica abrasive system produced a clinically acceptable SBS. The different types of brackets, adhesive materials, operator's technique and the calculated bracket base surface area may be reasons for the difference in the mean SBS for the brackets treated with $30 \mu \mathrm{m}$ silica coated aluminum oxide abrasive particles than our results.

Using heat for recycling was the only method that maintained the original design of the bracket base irregularities supplied by the manufacturer. Eye visualization and SEM examination confirmed these results as shown in figure 2. This group showed high mean SBS $(19.2 \pm 9.8 \mathrm{MPa})$ and a statistically significant difference compared to the $50 \mu \mathrm{m}$ sandblasting group.

Our results agreed with the other studies in that using heat for recycling results in acceptable SBS. But on the contrary the original method showed by Lew and Djeng reported ${ }^{11}$ a decrease in the SBS by $40-50 \%$, while in our study the results showed a mean SBS higher than 
the control new bracket. Moreover, Gaffey et $\mathrm{al}^{13}$ concluded that silanated heat treated brackets showed lower SBS than silanated with no heat treatment, despite acceptable SBS, which means that heat treatment decreases the mean SBS. One difference between the previous two studies and our study is that the brackets used in both studies were chemically retentive, While our study was conducted on mechanically retentive ceramic brackets which may have an influence on the results.

Silva $\mathrm{EA}^{44}$ reported that the heat treatment by air flux at $100^{\circ} \mathrm{C}$ for $60 \mathrm{~s}$ following treatment with $30 \mu \mathrm{m}$ silica coated aluminum oxide increased the SBS more than using $30 \mu \mathrm{m}$ silica coated aluminum oxide alone.

No apparent enamel damage was visible in any of the specimens in this study but that does not mean that it is not possible during debonding.

Replacing failed ceramic brackets with a new one is believed to be costly, so recycling is one of the methods to reduce the cost of the orthodontic treatment without decreasing SBS to a significant low value. Also along this study the time taken to remove all visible adhesive from the bracket base surface using both abrasive treatments was about 30 seconds and that was not a waste of time. On the other hand heat treatment method is effective but inapplicable as it need special equipment and more time. Finally clinicians must put in consideration the cost of recycling including the equipment's cost like: the micro-etcher, sandblasting powder for the abrasive treatment, furnace and ultrasonic bath for the heat treatment, in addition to the time required for recycling.

Perhaps for some clinicians it is worthy to replace the failed bracket with new one, but recycling with $30 \mu \mathrm{m}$ silica coated aluminum oxide abrasives is a chair-side time-effective promising method with SBS comparable to that of new brackets.

\section{CONCLUSIONS}

1. Reconditioning the mechanically retentive bracket with heat then followed by silane application resulted in a high SBS but it is time consuming.

2. No significant difference in the SBS between heat treated group followed by silane application and $30 \mu \mathrm{m}$ silica coated sandblasted group. 
Egyptian

Orthodontic Journal

3. Reconditioning by the application of $50 \mu \mathrm{m}$ aluminum oxide particles followed by silane application resulted in a significantly low SBS compared to all other groups.

4. Reconditioning with $30 \mu \mathrm{m}$ silica coated sandblast is a promising method as it is chair-side time-effective and show good and comparable SBS to that of new brackets.

\section{REFERENCES}

1. Britton J, McInnes P, Weinberg R, Ledoux W, Retief D. Shear bond strength of ceramic orthodontic brackets to enamel. Am J Orthod Dentofacial Orthop. 1990 Oct; 98(4):348-53.

2. Reynolds I. A review of direct orthodontic bonding. Br J Orthod. 1975; 2: 171-178.

3. Bishara S, Trulove T. Comparisons of different debonding techniques for ceramic brackets: an in vitro study, part I. Background and methods. Am J Orthod Dentofacial Orthop. 1990 Aug; 98(2):145-53.

4. Chaconas S, Caputo A, Niu G. Bond strength of ceramic brackets with various bonding systems. Angle Orthod. 1991 spring; 61(1):35-42.

5. Winchester L. Bond strengths of five different ceramic brackets: an in vitro study. Eur J Orthod. 1991 Aug; 13(4):293-305.

6. Joseph VP, Rossouw PE. The shear bond strengths of stainless steel and ceramic brackets used with chemically and light-activated composite resins. Am J Orthod Dentofacial Orthop 1990,97:121-125.

7. Swartz ML. A technical bulletin on the issue of bonding and debonding ceramic brackets. No. 070-5039. Glendora (CA): Ormco Corp., 1988.

8. Forsberg CM, Hagberg C. Shear bond strength of ceramic brackets with chemical or mechanical retention. Br J Orthod. 1992 Aug; 19(3):183-9.

9. Wang WN, Meng CL, Tarng TH. Bond strength: a comparison between chemical coated and mechanical interlock bases of ceramic and metal brackets. Am J Orthod Dentofacial Orthop. 1997 Apr; 111(4):374-81. 
Egyptian

Orthodontic Journal

10. Lew KKK, Djeng SK. Recycling ceramic brackets. J Clin Orthod. 1990 Jan; 24(1):44-7.

11. Lew KKK, Chew CL, Lee KW. A comparison of shear bond strengths between new and recycled ceramic brackets. Eur J Orthod. 1991 Aug; 13(4):306-10.

12. Zachrisson BU, Büyüky1lmaz T. Bonding in orthodontics. In: Graber TM, Vanarsdall RL, Vig KWL, editors. Orthodontics: current principles and techniques. St Louis: Elsevier; 2005. p. 588, 595.

13. Gaffey PG, Major PW, Glover K, Grace M, Koehler JR. Shear/peel bond strength of repositioned ceramic brackets. Angle Orthod. 1995; 65(5):351-7.

14. Chung $\mathrm{CH}$, Friedman DS, Mante FK. Shear bond strength of rebonded mechanically retentive ceramic brackets. Am J Orthod Dentofacial Orthop. 2002 Sep; 122(3):282-7.

15. Van der Veen LH, Jongebloed WL, Dijk F., Purdell-Lewis DJ, Van de Poel AC. SEM study of six retention systems for resin-to-metalbonding. Dent Mater. 1988 Oct; 4(5):266-71.

16. Lacy AM, LaLuz J, Watanabe LG, Dellinges M. Effect of porcelain surface treatment on the bond to composite. J Prosthet Dent. 1988 Sep; 60(3):288-91.

17. Calamia JR. Etched porcelain veneers: the current state of art. Quintessence Int. 1985 Jan; 16(1):5-12.

18. Goldstein RE, Parkins FM. Air-abraded technology: its new role in restorative dentistry. J Am Dent Assoc. 1994 May; 125(5):551-7.

19. Canay S, Kocadereli I, and Akca E. The effect of enamel air abrasion on the retention of bonded metallic orthodontic brackets. Am J Orthod Dentofacial Orthop. 2000 Jan; 117(1):15-9.

20. Hogervorst WW, Feilzer AJ, Prahl-Andersen B. The air-abrasion technique versus the conventional acid-etching technique: A quantification of surface enamel loss and a comparison of shear bond strength. Am J Orthod Dentofacial Orthop. 2000 Jan; 117(1):20-6. 
21. Reisner KR, Levitt HL, Mante F. Enamel preparation for orthodontic bonding: a comparison between the use of a sandblaster and current technique.Am J Orthod Dentofacial Orthop. 1997 Apr; 111(4):366-73.

22. Berk N, Basaran G, Özer T. Comparison of sandblasting, laser irradiation, and conventional acid etching for orthodontic bonding of molar tubes. Eur J Orthod. 2008 Apr; 30(2):183-9.

23. Harris AMP, Joseph VP, Roussouw PE. Shear/peel strengths of esthetic orthodontic brackets. Am J Orthod Dentofacial Orthop. 1992 Sep;102(3):215-9.

24. Frank Falkensammer, Erwin Jonke, Michael Bertl, Josef Freudenthaler and Hans Peter Bantleon. Rebonding performance of different ceramic brackets conditioned with a new silane coupling agent. European Journal of Orthodontics 35 (2013) 103-109

25. Guarita MK, Moresca AH, Losso EM1, Moro A, Moresca RC, CorrerGM. Effect of Different Surface Treatments for Ceramic Bracket Base on Bond Strength of Rebonded Brackets. Braz Dent J. 2015 Jan-Feb;26(1):61-5.

26. Toroglu MS, Yaylali S. Effects of sandblasting and silica coating on the bond strength of rebonded mechanically retentive ceramic brackets. Am J Orthod Dentofacial Orthop. 2008 Aug; 134(2):181e1-7.

27. Atsü S, Çatalbaş B, Gelgör İE. Effects of silica coating and silane surface conditioning on the bond strength of rebonded metal and ceramic brackets. J Appl Oral Sci. 2011 May-Jun; 19(3):233-9.

28. Daniel WW. Biostatistics. A foundation for analysis in health science 7 TH Edition. New York, Brisbane: John Wiley \& Sons, Inc. 1999.

29. A. Al Shamsi; J. L. Cunningham; P. J. Lamey; E. Lynch, Shear Bond Strength and Residual Adhesive after Orthodontic Bracket Debonding. (Angle Orthod 2006;76:694-699.)

30. Kukiattrakoon B, Samruajbenjakul B,Shear bond strength of ceramic brackets with various base designs bonded to aluminous and fluorapatite ceramics. European Journal of Orthodontic. 2010; 32: 87-93. 
31. Sirisha K, Rambabu T, Shankar YR, Ravikumar P. Validity of bond strength tests: A critical review: Part I.J Conserv Dent. 2014 Jul; 17(4):305-11.

32. Nakamichi I, Iwaku M, Fusayama T. Bovine teeth as possible substitutes in the adhesion test. J Dent Res. 1983 Oct; 62(10):1076-81.

33. Oesterle LJ, Shellhart WC, Belanger GK. The use of bovine enamel in bonding studies. Am J Orthod Dentofacial Orthop. 1998 Nov; 114(5):514-9.

34. Yassen GH, Platt JA, Hara AT. Bovine teeth as substitute for human teeth in dental research: A review of literature. J Oral Sci. 2011 Sep; 53(3):273-82.

35. Salz U, Bock T. Testing adhesion of direct restoratives to dental hard tissue - A review. J Adhes Dent. 2010 Oct; 12(5):343-71.

36. Perdigao J. Dentin bonding - Variables related to the clinical situation and the substrate treatment. Dent Mater. 2010 Feb; 26(2):e24-37.

37. Lee JJ, Nettey-Marbell A, Cook A Jr, Jr, Pimenta LA, Leonard R, Ritter AV. Using extracted teeth for research: The effect of storage medium and sterilization on dentin bond strengths. J Am Dent Assoc. 2007 Dec; 138(12):1599-603.

38. DeWald JP. The use of extracted teeth for in vitro bonding studies: A review of infection control considerations. Dent Mater. 1997 Mar; 13(2):74-81.

39. Dental materials - testing of adhesion to tooth structure. Second ed. Switzerland. Technical specification ISO/TS 11405; 2003.

40. Tamura Y, Tsubota K, Otsuka E, Endo H, Takubo C, Miyazaki M, et al. Dentin bonding Influence of bonded surface area and crosshead speed on bond strength. Dent Mater J. 2011; 30(2):206-11. 
41. Lindemuth JS, Hagge MS. Effect of universal testing machine crosshead speed on the shear bond strength and bonding failure mode of composite resin to enamel and dentin. Mil Med. 2000 Oct; 165(10):742-6.

42. Jena AK, Duggal R, Mehrotra AK. Physical Properties and Clinical Characteristics of Ceramic Brackets: A Comprehensive Review. Trends Biomater. Artif. Organs. 2007; 20: 101-5.

43. Ciocan DI, Stanciu D, Popescu MA, Miculescu F, Plotog I, Varzaru G, et al. Electron microscopy analysis of different orthodontic brackets and their adhesion to the tooth enamel. Rom J Morphol Embryol 2014, 55(2 Suppl):591-596.

44. Silva EA, Trindade FZ, Reskalla HN, Queiroz JR. Heat treatment following surface silanization in rebonded tribochemical silica-coated ceramic brackets: shear bond strength analysis. J Appl Oral Sci. 2013 Jul-Aug; 21(4):335-40. 